\title{
Specific imbalance of right and left sided motor neuron excitability in schizophrenia
}

\author{
DAVID J GOODE, ${ }^{*} \dagger$ ALEXANDER A MANNING $\dagger$ \\ From the Department of Psychiatry, ${ }^{*}$ Bowman Gray School of Medicine, Wake Forest University, \\ Winston-Salem, and the Clinical Research Unit, $\dagger$ Broughton Hospital, Morganton NC, USA
}

SUMMARY Fifty-three psychiatric patients, 16 with schizophrenia, 19 with affective disorder, and 19 with schizo-affective disorder were diagnosed by Research Diagnostic Criteria. Hoffmann reflex recovery curves were measured in the right and left legs of each patient. In both affective disorder and schizo-affective disorder, recovery curve height in the right and left legs was highly correlated. In schizophrenia, recovery curve height in the right and left legs was not correlated. These results demonstrate a right-left asymmetry in motor neuron excitability specific to schizophrenia. The findings are compatible with a deficit in hemispheric transfer that is unique to schizophrenia. Other interpretations can be made, including diffuse cortical or subcortical dysfunction in schizophrenia which disrupts transfer or interpretation or intrahemispheric communication.

Specific hemispheric dysfunction has been postulated in both schizophrenia and affective disorder; a dominant hemispheric dysfunction is characteristic of schizophrenia and a non-dominant hemispheric dysfunction characteristic of affective disorder. This theory was initially proposed on the basis of an association of schizophrenic disorder with bilateral or leftsided temporal lobe lesions and affective disorder with right-sided temporal lobe lesions in patients with both complex partial seizures and psychosis. ${ }^{1}$ It gained support from studies of EEG power spectral analysis, asymmetry of lateral ventricular size, dichotic listening, neuropsychological performance, skin conductance, and regional cerebral blood flow. However, work has not uniformly supported the hypothesis of specific hemispheric dysfunction. Alternate hypotheses have been proposed, including overactivation of an impaired left hemisphere in schizophrenia ${ }^{2}$ and impaired interhemispheric transfer in schizophrenia. ${ }^{3}$

Beaumont and Dimond ${ }^{1}$ originally hypothesised a deficit of interhemispheric transfer of information in schizophrenia based on tests of transfer of visual information. Other authors, using more sophisticated

Address for reprint requests: D J Goode, MD, Dept of Psychiatry, Bowman Grey School of Medicine, Wake Forest University, Winston-Salem, NC 27103, USA.

Received 15 September 1987 and in revised form 2 December 1987 Accepted 7 December 1987 techniques have failed to document a deficit in visual transfer. ${ }^{45}$ However, a focus of interest on measures of interhemispheric transfer of information has revealed deficits of transfer of stereognostic information in schizophrenic patients, ${ }^{67}$ but findings have not been consistent. ${ }^{8}$ Data based on differential latencies of somatosensory evoked potentials on contralateral and ipsilateral sides have supported a defect in callosal conduction in schizophrenic patients, ${ }^{9-11}$ but these have not been consistently supported. ${ }^{12}$ In addition, anatomic studies have demonstrated abnormalities of the corpus callosum in schizophrenic patients. ${ }^{13-15}$ Deficiencies in interhemispheric transfer of information in schizophrenia have been reviewed both positively ${ }^{1617}$ and negatively. ${ }^{18}$

Abnormalities of the Hoffmann reflex (H-reflex) recovery curve in psychotic patients have been reported. ${ }^{19-22}$ More recent studies have shown right-left differences in recovery curve height to be significantly related to psychopathology 2123 and diagnosis (Goode and Manning, submitted for publication). Generally these data have supported hypothesised left hemispheric dysfunction in schizophrenia and right hemispheric dysfunction in affective disorder.

We report an investigation of bilateral recovery curve measurement in a drug-free population of patients with schizophrenia, schizo-affective disorder, and affective disorder. Correlations between right and left sided recovery curve height were made for each diagnostic group. 


\section{Methods}

Patient population Fifty-three patients who were hospitalised on the Clinical Research Unit of Broughton were studied. All patients participated voluntarily in the study and were aware of the nature and purpose of the research. All indicated their willingness to participate by means of written informed consent. Diagnoses were based on the Research Diagnostic Criteria. ${ }^{24}$ The table summarises diagnostic and demographic data of the patient population.

$H$ reflex measures Techniques of $\mathrm{H}$-reflex measurement have been previously described. ${ }^{202123}$ Measurements were performed in a quiet, darkened room while the subjects were comfortably seated in a reclining chair with the tested leg extended and supported on the footrest by a rolled towel at the ankle. Skin at recording and stimulation sites was cleansed with alcohol. Recording electrodes (Beckman silver-silver chloride) were affixed $2 \mathrm{~cm}$ apart below the gastrocnemius, directly over the soleus muscle. A large ground electrode was attached over the upper posterior calf between recording and stimulating electrodes. Stimulating electrodes (silver-silver chloride discs imbedded in a lucite holder) were firmly fixed over the posterior tibial nerve in the popliteal fossa by means of an adjustable holder. Position was adjusted to produce a large reproducible $\mathrm{H}$-reflex response. Electrical contact between electrodes and skin was provided by Beckman electrode jelly. Measurements were made in the right leg first and the left leg second in all cases. Previous work has shown that order of testing does not affect differences in recovery curve height between the right and left leg. ${ }^{25}$ Square wave stimulus pulses $1 \mathrm{~ms}$ in duration were generated by a Grass Model S88 stimulator with Stimulus Isolation Unit. Electromyographic signals from the soleus muscle were amplified and displayed on a storage oscilloscope for measurement. Single stimulus pulses were delivered at low voltage, increasing by $10 \mathrm{~V}$ increments until the maximum amplitude $\mathrm{H}$-reflex was attained. Stimulus interval during localisation of maximum was a minimum of 20 seconds. Subjects in whom the maximal H-reflex did not exceed $2 \mathrm{mV}$ were not tested. At the stimulus intensity for the maximum $\mathrm{H}$-reflex, paired stimuli were delivered at stimulus intervals of $50,100,150,200,250$, and $300 \mathrm{~ms}$. From the stored oscilloscope trace, the height of the $\mathrm{H}$-reflex produced by the second stimulus pulse (H2) was compared with the height of the $\mathrm{H}$-reflex produced by the first stimulus pulse (H1) and estimated as a percentage $(\mathrm{H} 1 / \mathrm{H} 2 \%)$. The recovery curve was generated by graphing $\mathrm{H} 2 / \mathrm{H} 1 \%$ versus stimulus interval. Test intervals for recovery curve determination

Table Diagnostic and demographic data of the patient population

\begin{tabular}{llll}
\hline & Diagnosis & & \\
\cline { 2 - 4 } & Schizophrenia & Affective & Schizo-affective \\
\hline Number & & & \\
Males & 12 & 10 & 8 \\
Females & 4 & 9 & 11 \\
Total & 16 & 19 & 19 \\
Age (yr) & 27.7 & 35.9 & 27.2 \\
Mean & 6.1 & 10.0 & 7.2 \\
SD & & & \\
\hline
\end{tabular}

was 60 seconds. Two parameters derived from the recovery curve were used for analysis. The mean value of $\mathrm{H} 2 / \mathrm{H} 1 \%$ over the measured stimulus intervals $(50-300 \mathrm{~ms})$ was termed mean recovery curve height and the maximum value observed was identified as Hmax.

\section{Results}

Mean recovery curve height and $H$ max of the right and left legs were compared for each diagnostic group. Figure 1 presents a plot of right leg mean recovery curve height versus left leg mean recovery curve height for each of the three diagnostic groups, schizophrenia (a), affective disorder (b), and schizo-affective disorder (c). Similarly, fig 2 presents a plot of right leg Hmax versus left leg $\mathrm{Hmax}$ for each diagnostic group. Pearson correlation coefficients relating right leg values to left leg values of mean recovery curve height and Hmax for each diagnostic group revealed the following relations: For the schizophrenic diagnostic group, right and left values of mean recovery curve height and Hmax were not significantly correlated (mean recovery curve height: $\mathrm{r}=0.081$, $\mathrm{df}=14, \mathrm{p}=$ NS; Hmax: $r=0.033$, df $=14, p=N S)$. Right and left values of both mean recovery curve height and Hmax were significantly correlated for both the affective disorder diagnostic group (mean recovery curve height: $r=0.703$, df $=17, \mathrm{p}<0.001$; Hmax: $\mathrm{r}=0.476, \mathrm{df}=17, \mathrm{p}<0.05)$ and the schizo-affective disorder diagnostic group (mean recovery curve height: $r=0.766, \mathrm{df}=16, \mathrm{p}<0.001$; Hmax: $\mathrm{r}=$ 0.831 , df $=16, p<0.001)$.

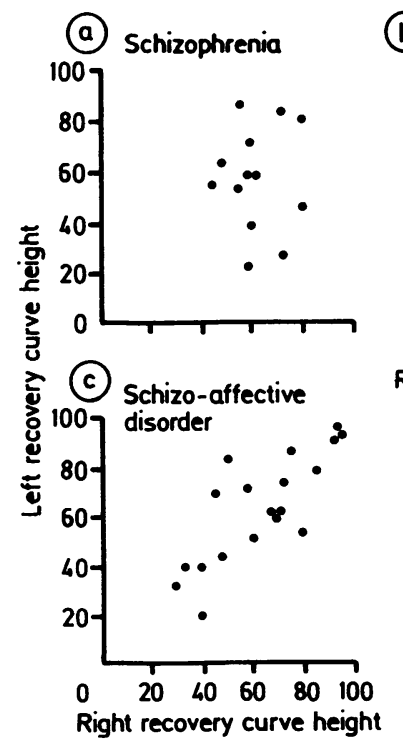

Fig 1 Plot of mean recovery curve height for right leg versus left leg. (a) Schizophrenia. (b) Affective disorder. (c) Schizo-affective disorder. 


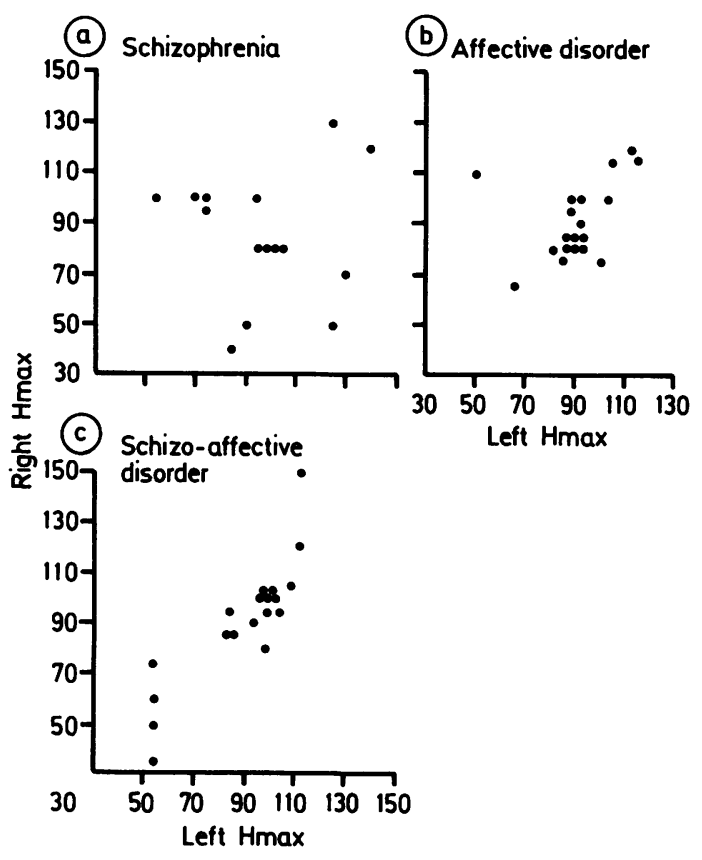

Fig 2 Plot of Hmax for right leg versus left leg. (a) Schizophrenia. (b) Affective disorder. (c) Schizo-affective disorder.

\section{Discussion}

The results are indicative of a right-left dissociation in degree of motor neuron excitability that is diagnostically specific for schizophrenia. In both the affective disorder and the schizo-affective diagnostic group, motor neuron excitability was found to be symmetrical in the right and left legs. These findings are supportive of the concept of a deficit in interhemispheric connection specific to schizophrenia hypothesised by Beaumont and Dimond. ${ }^{3}$ The methodology of the present study has some advantage in that the testing is independent of variables of attention and cooperation in reporting, which may be impaired in the schizophrenic patient. Since the Hoffmann reflex recovery curve is affected by cortical and subcortical influences, our results may reflect subcortical right-left dissociation rather than cortical. However, evidence from evoked potential and anatomic studies support a defect of the corpus callosum. ${ }^{9-15}$

Previous evidence from our work have shown that the magnitude of right-left differences in recovery curve height is correlated with degree of psychopathology in schizophrenic and schizo-affective patients. ${ }^{23}$ It is quite possible that the right-left differences reflect a rough degree of dissociation between the hemispheres or subcortically, and the degree of dissociation is in fact more closely related to degree of psychopathology in these diagnostic groups. Such a dissociation may reflect a true disconnection derived from callosal pathology or might reflect unilateral or bilateral diffuse dysfunction at the hemispheric or subcortical level sufficient to degrade information from the other hemisphere. However, such a disruption would have to be severe to affect motor neuron excitability to the degree reported here. Measurable changes in Hoffmann reflex activity have been reported after severe disturbances of motor centres, such as stroke and Parkinson's disease. ${ }^{26-28}$

The data from this study are supportive of a deficit of hemispheric transfer specific to schizophrenia. This is reflected by an asymmetrical activation of spinal motor neurons as measured by recovery curve height. This asymmetry is not present in either affective disorder or schizo-affective disorder. The similarity in findings in schizo-affective disorder and affective disorder, distinct from those in schizophrenia, support a closer relation between schizo-affective disorder and affective disorder with respect to lack of evidence for asymmetry of motor neuron excitability and hemispheric disconnection. Since the postulated hemispheric disconnection is clearly not present in the schizo-affective subgroup, this may explain differences in findings with respect to this hypothesis when more exclusive diagnostic criteria for schizophrenia have not been used.

\section{References}

1 Flor-Henry P. Psychosis and temporal lobe epilepsy-controlled investigation. Epilepsia 1969;10:363.

2 Gur R. Left hemisphere dysfunction and left hemisphere overactivation in schizophrenias. J Abnorm Psychol 1978;87: 226-38.

3 Beaumont JG, Dimond SJ. Brain disconnection and schizophrenia. B J Psychiatry 1973;123:661-2.

4 Tress KH, Kugler BT, Caudrey DJ. Interhemispheric integration in schizophrenia. Gruzelier J, Flor-Henry P, eds. Hemisphere Asymmetries of Function in Psychopathology. Amsterdam Elsevier/North Holland Biomedical Press 1979:449-62.

5 Maragao, Page. Brain disconnection, schizophrenia, and paranoia. J Nerv Ment Dis 1983;171(3):133-40.

6 Dimond SJ, Scammell RE, Pryce IG, Huws D, Gray C. Callosal transfer and left-hand anomina in schizophrenia. Biol Psychiatry 1979;14:735-9.

7 Carr S Aw. Interhemispheric transfer of stereognostic information in chronic schizophrenics. Br J Psychiatry 1980;136:53-8.

8 Wade, Taylor. Interhemispheric transfer in schizophrenia and affective disorder. Biol Psychiatry 1984;19:107-11.

9 Jones, Gareth, Miller JJ. Functional tests of the corpus callosum in schizophrenia. Br J Psychiatry 1981;139:553-7.

10 Gulmann NC, Wildschiodtz G, Orbaek K. Alteration of interhemisphere conduction through corpus callosum in chronic schizophrenia. Biol Psychiatry 1982;17:585-94.

11 Tress KH, Caudrey DJ, Mehta B. Tactile-evoked potentials in schizophrenia interhemispheric transfer and drug effects. $\boldsymbol{B r} \boldsymbol{J}$ 
Psychiatry 1983;143:156-64.

12 Shagass C, Josiassen R, Rowmer R, Straumanis J, Slepner S. Failure to replicate evoked potential observations suggesting corpus callosum dysfunction in schizophrenia. Br J Psychiatry 1983;142:471-6.

13 Nasrallah HA, McCalley-Whitters M, Bigelow LB, Rauscher FP. A histological study of the corpus callosum in chronic schizophrenia. Psychiatry Res 1983;8:251-60.

14 Bigelow LB, Nasrallah HA, Rauscher FP. Corpus callosum thickness in chronic schizophrenia. Br J Psychiatry 1983;142: 284-7.

15 Nasrallah HA, Andreasen NC, Coffman JA et al. A controlled magnetic resonance imaging study of corpus callosum thickness in schizophrenia. Biol Psychiatry 1986;21:274-82.

16 Green P, Glass A, O'Callaghan MAJ. Some implications of abnormal hemisphere interaction in schizophrenia. Gruzelier J, Flor-Henry P, eds. Hemisphere Asymmetries of Function in Psychopathology. Amsterdam Elsevier/North Holland Biomedical Press 1979:431-48.

17 Butler S. Gruzelier J, Flor-Henry P, eds. Hemisphere Asymmetries of Function in Psychopathology. Amsterdam Elsevier/North Holland Biomedical Press 1979:47-58.

18 Walker E, McGuire M. Intra- and interhemispheric information processing in schizophrenia. Psychol Bull 1982;92(3).

19 Crayton JW, Meltzer HY, Goode DJ. Motoneuron excitability in psychiatric patients. Biol Psychiatry 1977;12:545.

20 Goode DJ, Meltzer HY, Mazura TA. Physiologic abnormalities of the neuromuscular system in schizophrenia. Schizophrenia Bull 1977;3:121-38.

21 Goode DJ, Meltzer HY, Mazura TA. Hoffmann reflex abnormalities in psychotic patients. Biol Psychiatry 1979;14:95-110.

22 Metz J, Goode DJ, Meltzer HY. Descriptive studies of H-reflex recovery curves in psychiatric patients. Psychol Med 1980;10: 541-8.

23 Goode DJ, Manning AA. Variations in the Hoffmann reflex recovery curve related to clinical manifestations of schizoaffective disorder. Psychiatry Res 1985;15:63-70.

24 Feighner JP, Robins E, Guze SB, Woodruff RA, Winokur G, Munoz R. Diagnostic criteria for use in psychiatric research. Arch Gen Psychiatry 1972;26:57.

25 Goode DJ, Glenn S, Manning AA, Middleton JF. Lateral asymmetry of the Hoffmann reflex: relation to cortical laterality. $J$ Neurol Neurosurg Psychiatry 1980;43:831-5.

26 McLeod JG, Walsh JC. H-reflex studies in patients with Parkinson's disease. J Neurol Neurosurg Psychiatry 1972;35:77-80.

27 Diamantopoulos E, Olsen PF. Excitability of notor neurones in spinal shock in man. J Neurol Neurosurg Psychiatry 1967; 30:427-31.

28 Garcia-Mullin R, Mayer RF. H-reflexes in acute and chronic hemiplegia. Brain 1972;95:559-72. 